\title{
anu \\ DNA Methylation in INA, NHLH2, and THBS4 Is Associated with Metastatic Disease in Renal Cell Carcinoma
}

\author{
Olga Katzendorn ${ }^{1,+}$, Inga Peters ${ }^{1,+}{ }^{\mathbb{D}}$, Natalia Dubrowinskaja ${ }^{1}$, Joana M. Moog ${ }^{1}$, Christel Reese ${ }^{1}$, \\ Hossein Tezval ${ }^{1}$, Pouriya Faraj Tabrizi ${ }^{1}$, Jörg Hennenlotter ${ }^{2}{ }^{D}$, Marcel Lafos ${ }^{3}$, Markus A. Kuczyk ${ }^{1}$ \\ and Jürgen Serth ${ }^{1, *}$
}

1 Department of Urology and Urologic Oncology, Hannover Medical School, 30625 Hannover, Germany; katzendorn.olga@mh-hannover.de (O.K.); peters.inga@mh-hannover.de (I.P.); dubrowinskaja.natalia@mh-hannover.de (N.D.); moog.joana@googlemail.com (J.M.M.); Reese.Christel@mh-hannover.de (C.R.); tezval.hossein@mh-hannover.de (H.T.); FarajTabrizi.Pouriya@mh-hannover.de (P.F.T.); kuczyk.markus@mh-hannover.de (M.A.K.)

2 Department of Urology, Eberhard Karls University of Tuebingen, 72076 Tuebingen, Germany; Joerg.Hennenlotter@med.uni-tuebingen.de

3 Department of Pathology, Hannover Medical School, 30625 Hannover, Germany; Lafos.Marcel@mh-hannover.de

* Correspondence: Serth.Juergen@mh-hannover.de; Tel.: +49-511-532-6673

+ These authors contributed equally to this work.

check for updates

Citation: Katzendorn, O.; Peters, I.; Dubrowinskaja, N.; Moog, J.M.;

Reese, C.; Tezval, H.; Faraj Tabrizi, P.; Hennenlotter, J.; Lafos, M.; Kuczyk, M.A.; et al. DNA Methylation in INA, NHLH2, and THBS4 Is Associated with Metastatic Disease in Renal Cell Carcinoma. Cancers 2022, 14, 39. https://doi.org/10.3390/ cancers14010039

Academic Editor: Anja Rabien

Received: 13 November 2021

Accepted: 20 December 2021

Published: 22 December 2021

Publisher's Note: MDPI stays neutral with regard to jurisdictional claims in published maps and institutional affiliations.

Copyright: (c) 2021 by the authors. Licensee MDPI, Basel, Switzerland. This article is an open access article distributed under the terms and conditions of the Creative Commons Attribution (CC BY) license (https:// creativecommons.org/licenses/by/ $4.0 /)$.
Simple Summary: Early prediction of aggressive cancer using biomarkers is thought to be important for future improvements in the personalized treatment of renal cell carcinoma (RCC). Epigenetic alterations, such as DNA methylation, are promising candidates because they are frequently associated with distant metastasis of tumors and combinations of them offer greater informativity. Here, we describe the indication of the metastatic disease state of renal cell tumors by the methylation of three new candidate genes, INA, NHLH2, and THBS4. The inclusion of the methylation status of these genes could improve the early detection of metastatic tendency in renal tumors and help identify patients who will benefit from adjuvant treatments.

Abstract: The detection of DNA methylation in primary tumor tissues could be relevant for early stratification of aggressive renal cell carcinomas (RCCs) as a basis for future personalized adjuvant therapy. Methylated TCGA KIRC based candidate CpG loci in INA, NHLH2, and THBS4 that are possibly associated with RCC metastasis were evaluated by pyrosequencing in 154 paired normal adjacent and primary tumor tissues, as well as in 202 metastatic tissues. Statistical analysis was carried out by bivariate logistic regression for group comparisons, log rank survival analysis, and unsupervised and supervised analysis for the classification of tumors. Increased methylation of INA, NHLH2, and THBS4 loci were significantly associated with distant metastasis in primary tumors $(p<0.05)$, tissue-specific hypermethylation in metastatic $\left(p=7.88 \times 10^{-8}, 5.57 \times 10^{-10}, 2.06 \times 10^{-7}\right)$ and tumor tissues $\left(p=3.72 \times 10^{-24}, 3.17 \times 10^{-13}, 1.58 \times 10^{-19}\right)$, and shortened progression free survival in patients $(p=0.03)$. Combined use of $\mathrm{CpG}$ site-specific methylation permits the discrimination of tissues with metastatic disease and reveals a significant contribution of $\mathrm{CpG}$ sites in all genes to the statistical classification model. Thus, metastasis in RCC is significantly associated with methylation alterations in INA, NHLH2, and THBS4 loci, providing independent information for the potential early detection of aggressive renal cancers as a rationale for stratifying patients to adjuvant therapies.

Keywords: renal cell carcinoma; metastasis; NHLH2; INA; THBS4; hypermethylation; signature; prognosis

\section{Introduction}

Renal cell carcinoma (RCC) is the most common kidney neoplasia and is observed in 5\% and 3\% of all cancer diagnoses in men and women, respectively [1]. Although the majority of RCCs are diagnosed incidentally in early stages of the tumor on abdominal 
imaging, up to $25 \%$ of patients present with metastases at the time of diagnosis [2]. Though therapeutic approaches have evolved substantially in the last few decades, the 5-year survival of patients with metastatic disease is still poor [3,4]. Clinical predictions and risk stratification for localized and metastatic RCC currently rely on combined clinical, histological, and laboratory parameters summarized in risk score models, such as the stage, size, grade, and necrosis (SSIGN) score or the University of California Integrated Staging System (UISS). In contrast, biomarker stratification for disease prognosis or prediction is still at the beginning of development, and available clinical scores or biomarkers exhibit a lack of validation for non-metastatic localized RCC [5-8]. Taking into account that even patients with a clinicopathologically defined localized disease may develop aggressive disease, the need for biomarkers able to guide subsequent clinical decisions based on personalized adjuvant treatment strategies, appears to be evident [6,9]. This is further underlined by recent therapeutic advances demonstrating that subsets of localized RCC with a higher recurrence risk (tumor stage $\mathrm{T} \geq 2$, differentiation $\geq$ G3) likely benefit from adjuvant therapy with pembrolizumab, a PD-1 checkpoint inhibitor [10]. Moreover, considering that approximately one-third of these patients present with grade 3 and higher adverse events, individualized biomarker-based prediction of response or non-response could reduce non-beneficial treatments [10,11].

Recently, The Cancer Genome Atlas (TCGA) project substantially contributed to a detailed molecular characterization of RCC, providing substantial information about genetic and epigenetic alterations in different histological subtypes of RCC, such as the most common entity described in the Kidney RCC (KIRC) database, clear cell RCC (ccRCC) [12,13]. The KIRC project reported highly individual mutation profiles, indicating that the use of prospective clinical detection of mutations in risk stratification models and personalized therapeutic approaches is basically limited [12]. In contrast, DNA methylation has not only been demonstrated to occur frequently in RCC, but has also been shown to be associated with a number of clinically relevant adverse parameters [14,15]. Therefore, a substantial number of studies, including our work, have revealed specific associations between DNA methylation and unfavorable histopathological characteristics [16-20], metastatic disease [16-19,21], shorter recurrence-free or cancer-specific survival [15-17,19,22-25] and the predicted response to anti-angiogenic therapy [26,27].

Although a significant number of epigenetic alterations have shown strong associations with clinicopathological parameters, no biomarker or marker panel has been translated into clinical routine. The reasons for this appear to be complex and include circumstances, such as the broad application of retrospective study designs, the limited informativity of single marker studies, and the limited size of patient cohorts, leading to sampling and selection bias and other restrictions [28,29].

To improve the informativity of DNA methylation-based detection and/or prediction of metachronous metastatic disease, we biometrically analyzed the KIRC database and identified internexin neuronal intermediate filament protein alpha (INA), nescient helixloop-helix 2 (NHLH2), and thrombospondin 4 (THBS4) as candidate genes showing an association between methylation and distant metastasis.

INA is a neuronal cytoskeletal intermediate filament expressed during neuronal development and forms homo- and hetero-polymeric filaments with other neuronal filaments. The physiological function of INA is still unclear [30,31]. In malignant disease, expression of INA at the protein level is associated with better progression free survival (PFS) and longer overall survival (OS) from gliomas and glioblastomas [32,33]. Accordingly, loss of INA expression correlates with adverse histopathological characteristics and worse prognosis in gastroenteropancreatic neuroendocrine neoplasms [34,35]. Moreover, an association of INA hypermethylation with worse histopathological characteristics has been described [34]. Interestingly, in gastrointestinal neuroendocrine neoplasms and colorectal cancer, INA hypermethylation is associated with a loss of expression, suggesting epigenetic silencing via hypermethylation $[34,36]$. 
NHLH2 is a neuronal basic helix-loop-helix (bHLH) transcription factor characterized by a basic DNA binding motif and HLH binding site forming heterodimers or homodimers with other transcription factors $[37,38]$. NHLH2 has been linked to the regulation of hypothalamic gene expression, body weight control, and hypogonadism in mice $[39,40]$. In primary neuroblastoma, overexpression of NHLH2 protein is associated with poor patient survival [41].

THBS4 is an extracellular calcium-binding glycoprotein that interacts with cell surfaces or components of the extracellular matrix (ECM) [42]. This protein mediates tissue remodeling and is involved in wound healing and angiogenesis [42,43]. Overexpression of both THBS4 protein and mRNA has been demonstrated in different urological and gastrointestinal solid tumors with increased potency of cellular invasion in vitro [44-46]. An association of higher levels of THBS4 protein and worse clinicopathological characteristics has been found in gastric and hepatocellular carcinoma $[45,47]$. In contrast, other studies have reported lower levels of THBS4 protein and hypermethylation of THBS4 in colorectal cancer, cutaneous T-cell lymphoma, and bladder cancer with an indication of epigenetic silencing in these tumors [48-50].

In the present study, we analyzed DNA methylation of INA, NHLH2, and THBS4 in normal, tumor, and metastatic renal tissue samples and found tissue-specific hypermethylation associated with the metastatic disease state, adverse clinical parameters, and shorter PFS. We also demonstrate that combined information on the methylation signature allows the identification of metastatic disease in unknown tissue samples with good accuracy.

\section{Materials and Methods}

\subsection{In Silico Analysis to Identify Candidate Loci}

Level 3 data from the TCGA KIRC HM450k methylation dataset and statistical software $R$ version 3.6.1 were used to identify metastasis-associated candidate loci in a univariate logistic regression analysis comparing independent tissue sample data between non-metastasized (M0) and metastasized primary tumors (M+) [12,51]. Results were adjusted using the Benjamini-Hochberg correction for multiple statistical testing and ranked by calculating the product of fold-change in group means and the logarithm of reciprocal $p$-values.

\subsection{Study Design}

Gene-wise averaged CpG site-relative methylation values were used to analyze potential associations between gene-related methylation and clinical features in a cross-sectional study. A subset of patients with corresponding data was subjected to analysis of PFS. Moreover, paired tumor-adjacent histopathological normal (adN) and tumor tissues (TU) were compared to detect tumor-specific hypermethylation, and tumor samples with absent distant metastasis status (M0) were compared to an independent tissue cohort of metastatic tissue samples (Mtx) to detect metastasis-specific hypermethylation. Case-control comparisons of primary RCC tissue samples with localized disease and samples with metastatic disease or metastatic tissue samples were used for statistical classification and to determine diagnostic parameters after a random split into equally sized training and test cohorts.

\subsection{Study Cohort}

A total of 189 RCC tumor tissues, 154 paired adN tissues, and 202 metastases from 100 patients with metastatic RCC disease were subjected to methylation analysis. Patient characteristics are summarized in Table 1 . The characteristics of the metastatic tissue cohort and the tissue sampling, TNM classification, grading, and tissue treatment were described previously [21,52]. Ethical approval was obtained from the ethical boards of Eberhard Karls University Tübingen and Hanover Medical School (no. 128/2003V and 1213-2011; approved on 14 October 2011). Written informed consent was obtained from all patients. The study was performed in accordance with the Helsinki Declaration. 
Table 1. Patient's clinical and histopathologic characteristics.

\begin{tabular}{|c|c|c|c|c|c|}
\hline \multicolumn{2}{|c|}{$\begin{array}{c}\text { Clinical and Pathological } \\
\text { Characteristics }\end{array}$} & \multirow{2}{*}{$\begin{array}{c}\text { Total Number of } \\
\text { Patients (allRCC), } \\
\boldsymbol{n}(\%)\end{array}$} & \multirow{2}{*}{$\begin{array}{c}\text { Subset of Patients } \\
\text { with ccRCC, } \\
\boldsymbol{n}(\%)\end{array}$} & \multirow{2}{*}{$\begin{array}{c}\text { Subset of Patients } \\
\text { with FU for allRCC, } \\
\boldsymbol{n}(\mathbf{\%}) \\
77(100.0)\end{array}$} & \multirow{2}{*}{$\begin{array}{c}\begin{array}{c}\text { Subset of Patients } \\
\text { with FU for ccRCC, } \\
\boldsymbol{n}(\mathbf{\%})\end{array} \\
57(100.0)\end{array}$} \\
\hline & Total cases & & & & \\
\hline \multirow[t]{4}{*}{ Histology } & ccRCC & 151 (79.9) & 151(100.0) & $57(74.0)$ & $57(100.0)$ \\
\hline & pap. RCC & $25(13.2)$ & $0(0.0)$ & $17(22.1)$ & $0(0.0)$ \\
\hline & chrom. RCC & $3(1.6)$ & $0(0.0)$ & $2(2.6)$ & $0(0.0)$ \\
\hline & Mixed histology * & $10(5.3)$ & $0(0.0)$ & $1(1.3)$ & $0(0.0)$ \\
\hline \multirow[t]{2}{*}{ Sex } & Female & $70(37.0)$ & $59(39.1)$ & $27(35.1)$ & $22(38.6)$ \\
\hline & Male & $119(63.0)$ & $92(60.9)$ & $50(64.9)$ & $35(61.4)$ \\
\hline \multirow[t]{2}{*}{ Age (years) } & Median & 65 & 65 & 65 & 64 \\
\hline & $(\min -\max )$ & $(35-91)$ & $(35-90)$ & (37-91) & (37-90) \\
\hline \multirow[t]{3}{*}{ Metastasis } & M0 & $156(82.5)$ & $123(81.5)$ & $59(76.6)$ & $41(71.9)$ \\
\hline & $\mathrm{M}+$ & $30(15.9)$ & $25(16.6)$ & $18(23.4)$ & $16(28.1)$ \\
\hline & na & $3(1.6)$ & $3(2.0)$ & $0(0.0)$ & $0(0.0)$ \\
\hline \multirow{3}{*}{$\begin{array}{l}\text { Lymph node } \\
\text { status }\end{array}$} & No & $168(88.9)$ & $136(90.1)$ & $70(90.9)$ & $52(91.2)$ \\
\hline & $\mathrm{N}+$ & $16(8.5)$ & $10(6.6)$ & $7(9.1)$ & $5(8.8)$ \\
\hline & na & $5(2.6)$ & $5(3.3)$ & $0(0.0)$ & $0(0.0)$ \\
\hline \multirow[t]{10}{*}{ Tumor stage } & pT1 & $11(5.8)$ & $8(5.3)$ & $8(10.4)$ & $5(8.8)$ \\
\hline & pT1a & $62(32.8)$ & $48(31.8)$ & $24(31.2)$ & $15(26.3)$ \\
\hline & pT1b & $46(24.3)$ & $38(25.2)$ & $13(16.9)$ & $9(15.8)$ \\
\hline & pT2 & $9(4.8)$ & $7(4.6)$ & $6(7.8)$ & $5(8.8)$ \\
\hline & pT3 & $5(2.6)$ & $2(1.3)$ & $2(2.6)$ & $1(1.8)$ \\
\hline & pT3a & $17(9.0)$ & $14(9.3)$ & $4(5.2)$ & $4(7.0)$ \\
\hline & $\mathrm{pT} 3 \mathrm{~b}$ & $32(16.9)$ & $30(19.9)$ & $18(23.4)$ & $17(29.8)$ \\
\hline & pT3c & $4(2.1)$ & $3(2.0)$ & $2(2.6)$ & $1(1.8)$ \\
\hline & pT4 & $1(0.5)$ & $0(0.0)$ & $0(0.0)$ & $0(0.0)$ \\
\hline & na & $2(1.1)$ & $1(0.7)$ & $0(0.0)$ & $0(0.0)$ \\
\hline \multirow[t]{6}{*}{ Differentiation } & G1 & $36(19.0)$ & $32(21.2)$ & $14(18.2)$ & $12(21.1)$ \\
\hline & G1-2 & $20(10.6)$ & $13(8.6)$ & $10(13.0)$ & $4(7.0)$ \\
\hline & G2 & $104(55.0)$ & $82(54.3)$ & $42(54.5)$ & $30(52.6)$ \\
\hline & G2-3 & $10(5.3)$ & $6(4.0)$ & $5(6.5)$ & $5(8.8)$ \\
\hline & G3 & $18(9.5)$ & $17(11.3)$ & $6(7.8)$ & $6(10.5)$ \\
\hline & na & $1(0.5)$ & $1(0.7)$ & $0(0.0)$ & $0(0.0)$ \\
\hline
\end{tabular}

Abbreviations: ccRCC clear cell renal cell carcinoma (RCC); pap. RCC papillary RCC; chrom. RCC chromophobe RCC; FU follow-up; na not available; * mixed histology defined as fractions of different histologic subtypes of RCC (ccRCC + pap. RCC, ccRCC + chrom. RCC).

\subsection{Nucleic Acid Extraction and DNA Bisulfite Conversion}

Histological tumor cell content was estimated in control sections, DNA isolated from frozen sections and punches of formalin-fixed paraffin-embedded tissue samples, and bisulfite conversion of DNA carried out as reported previously [16,23].

\subsection{DNA Methylation Analysis}

Pyrosequencing, PCR reactions, and the preparation of pyrosequencing templates were carried out as described previously [16,22]. Pyrosequencing assays were designed by using PyroMark Assay Design 2.0 software (Qiagen, Hilden, Germany) and the hg19 genome assembly as provided by the UCSC table browser. Primer sequences, sequences to analyze, and genomic positions are presented in Table S1. The genomic context of target genes, annotated HM450K CpG sites, candidate loci, and sites covered by the pyrosequencing assay are presented in Figure 1. CpG sites amenable by pyrosequencing analysis and used for subsequent statistical evaluation are summarized in Table 2. 
a)

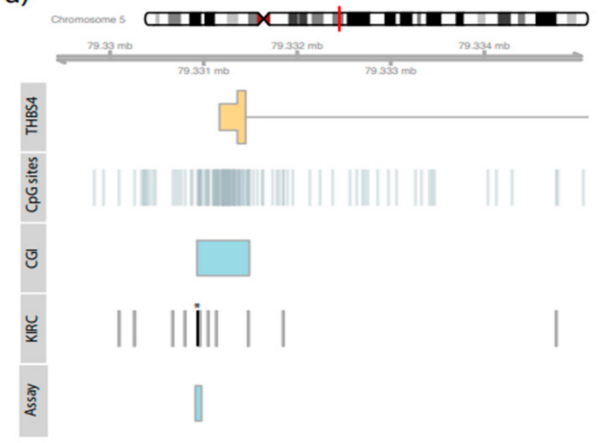

b)

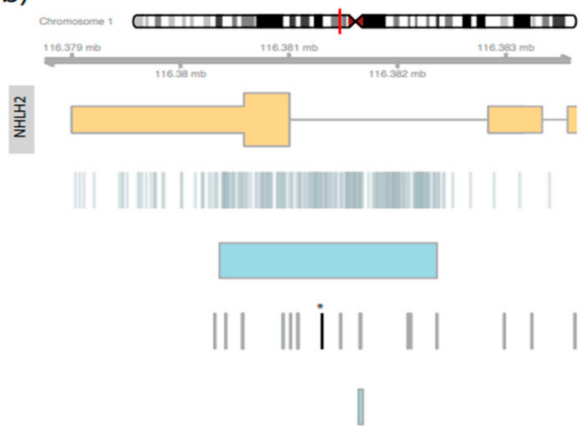

c)

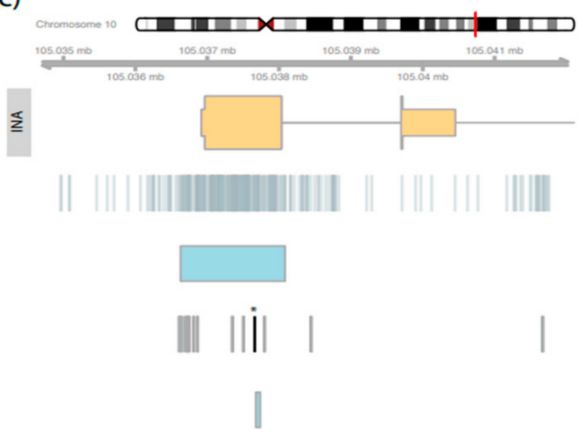

Figure 1. Localization of exons (higher part of orange rectangles) and the genomic regions corresponding to the 5'UTR (INA (c), THBS4 (a), or 3'UTR (NHLH2 (b)) (lower part of orange rectangles) are shown. $\mathrm{CpG}$ sites are annotated for the region (CpG sites), as well as the localization of $\mathrm{CpG}$ islands (CGI), positions of CpG sites considered in the KIRC study (KIRC), and the localization of pyrosequencing assays used (Assay). The asterisk (*) tags candidate CpG sites identified in the in silico analysis of the KIRC data.

Table 2. Genomic position of $\mathrm{CpG}$ sites amenable by pyrosequencing.

\begin{tabular}{cccc}
\hline Gene & Chromosome & Genomic Position Start & Genomic Position End \\
\hline \multirow{2}{*}{ INA } & \multirow{2}{*}{10} & $\begin{array}{c}105037691, \sim 700, \sim 703, \sim 706, \\
\sim 713, \sim 715, \sim 719, \sim 728\end{array}$ & $\begin{array}{c}105037692, \sim 701, \sim 704, \sim 707, \\
\sim 714, \sim 716, \sim 720, \sim 729\end{array}$ \\
& \multirow{2}{*}{1} & $116381644, \sim 46, \sim 48, \sim 52, \sim 64$, & $116381645, \sim 47, \sim 49, \sim 53, \sim 65$, \\
& & $\sim 67, \sim 79$ & $\sim 68, \sim 80$ \\
\hline \multirow{2}{*}{ THLH2 } & \multirow{2}{*}{5} & $79330930, \sim 44, \sim 56, \sim 58, \sim 60$, & $79330931, \sim 45, \sim 57, \sim 59, \sim 61$, \\
& & $\sim 63, \sim 69$ & $\sim 64, \sim 70$ \\
\hline
\end{tabular}

\subsection{Statistical Analysis}

All statistical analyses were performed in R version 3.6.1 software and program libraries as specified below [51]. Statistical tissue group comparisons were carried out using gene-wise aggregated methylation values obtained by calculating the corresponding means for CpG site-specific methylation values. Subgroup evaluations of the association with clinical or pathological parameters were performed in bivariate logistic regression models with age as the covariate and, if necessary, following dichotomization as specified. The time to progression of disease was analyzed by univariate log rank analysis. The optimized cut-off for dichotomization of methylation was approximated using the R package maxstat; relative methylation values for dichotomization were $24 \%$ for $I N A, 11 \%$ for $N H L H 2$, and $25 \%$ for THBS4 [53]. Metastatic tissue samples were compared to independent primary cancer tissues following patient-specific aggregation of measurements obtained for multiple metastases by calculating the mean metastatic tissue methylation value and logistic regression analysis. We applied the two-sided paired $t$-test to evaluate methylation in tumor and paired adN tissues.

Unsupervised and supervised statistical classification analyses of tissues were carried out by making use of $\mathrm{CpG}$ site-specific methylation data including 18 sites annotated to the three candidate gene regions of interest: INA, 7 sites; NHLH2, 4 sites; and THBS4, 7 sites. Missing data for unsupervised clustering analysis were imputed using the mice package for $R$ [54]. Comparisons of the efficiency of various clustering methods, including hierarchical agglomerative, divisive top-down clustering, and partitioning methods were carried out using the ClusterTool library and estimated Jaccard indices applied as a measure of the cluster stability [55]. Consensus clusters of 100 runs are presented as heatmaps using the Rpackage ComplexHeatmaps [56]. Explorative statistical analyses of the association between cluster class and metastatic disease state were carried out using the R package vcd [57]. 
For supervised statistical analyses, missing data were treated in a two-step procedure by sequentially removing patient samples with the maximum numbers of missing values and imputing residual absent values using the mice package for $R$ [54]. Random forest classification analysis was carried out following optimization of the random forest model parameters using the $\mathrm{R}$ libraries caret and ranger [58-60]. The final model diagnostic parameters were determined using the caret package [58]. The importance of variables was calculated and presented using the randomForestExplainer package [61].

\section{Results}

\subsection{In Silico Identification of Metastasis-Associated Methylated Loci Using KIRC Data}

KIRC methylation data for 282 tumor tissues were subjected to univariate logistic regression analysis comparing the subsets of $230 \mathrm{M} 0$ and $52 \mathrm{M}+$ tumors. Statistical evaluation identified CpG sites cg00824018, cg00065905, and cg00795341, which were annotated to INA, NHLH2, and TBHS4, respectively, as being among the top 20 ranked candidates. Associated mean fold changes in methylation were $1.68,1.55$, and 2.01 with corresponding $p$-values of $1.30 \times 10^{-34}, 1.72 \times 10^{-34}$, and $1.90 \times 10^{-19}$, respectively. A literature inquiry presented evidence of a functional or statistical association with tumorigenesis. Following a technical evaluation, whether the loci of the corresponding candidate genes are expected to be accessible to DNA methylation analysis was determined by pyrosequencing. Features of the pyrosequencing assays are summarized in Table S1 and illustrated in Figure 1.

\subsection{Association of INA, NHLH2, and THBS4 CpG Site Methylation with Adverse Clinicopathological Parameters and Worse PFS}

A statistical comparison of tumors with ccRCC and papillary histological classification using bivariate logistic regression including age as a covariate exhibited a negative association for the INA loci $(p=0.04$, odds ratio $(\mathrm{OR})=0.95,95 \%$ confidence interval $(\mathrm{CI})$ : 0.91-0.99), whereas THBS4 loci methylation exclusively demonstrated an association with patient sex in the whole cohort ( $p=0.04, \mathrm{OR}=1.03,95 \% \mathrm{CI}: 1.00-1.05)$ but not the ccRCC subgroup $(p=0.09$, OR = 1.03).

Therefore, we analyzed the possible associations between the candidate genes and the state of distant metastasis as the most relevant clinical parameter for both the complete cohort of tumors independent of the histological state of tissues (allRCC group) and the larger subset of clear cell tumors (ccRCC group). Notably, all of the candidate genes showed a significant association between methylation and the state of distant metastases (Figure $2 \mathrm{a}-\mathrm{c}$ ). Moreover, all of the clinical parameters widely used to estimate the aggressiveness of tumors, including tumor stage, status of lymph node metastasis, and grade of differentiation were significantly associated with higher methylation of the INA, NHLH2, and THBS4 candidate loci in both the allRCC and ccRCC groups (Table 3a,b). Survival analysis using available follow-up data for a subset of tumors demonstrated a possible significant association of higher tumor methylation and shortened time to disease progression in univariate log rank analyses for INA, NHLH2, and THBS4 methylation (Figure 3). 
a)

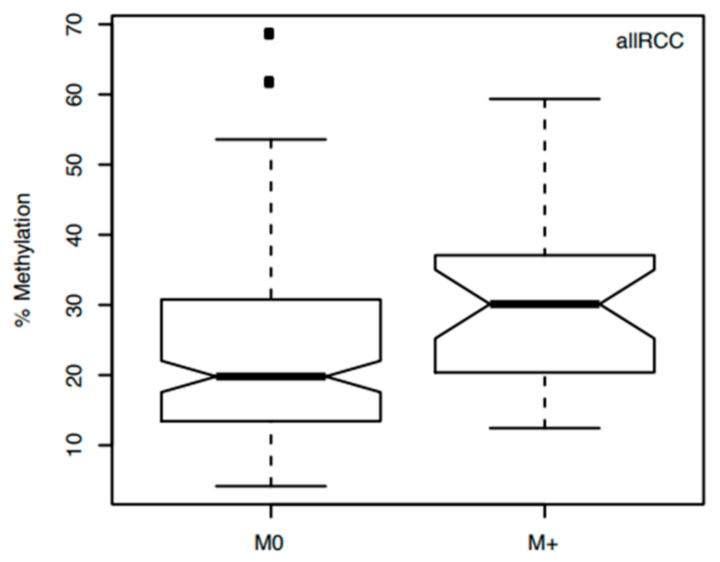

b)

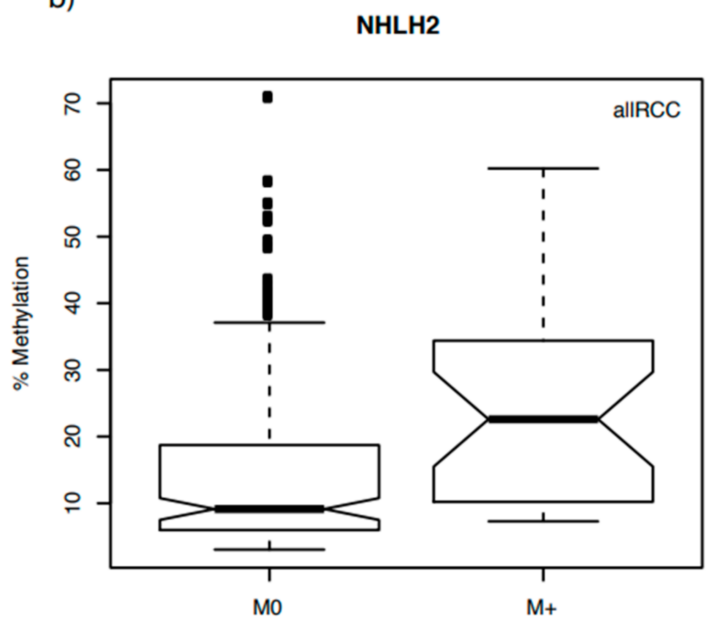

c)

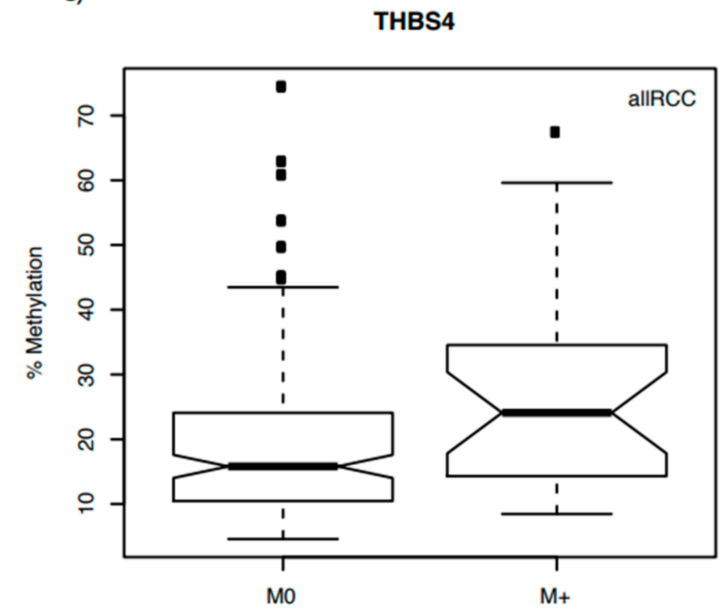

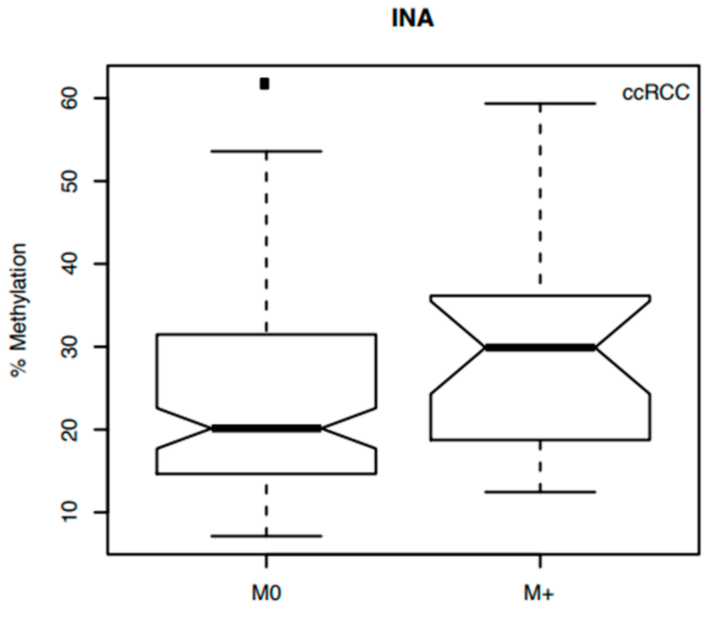

NHLH2

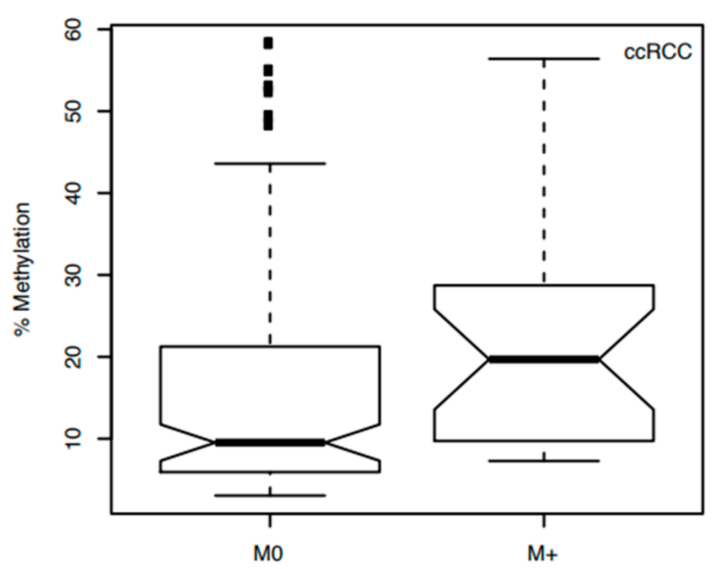

THBS4

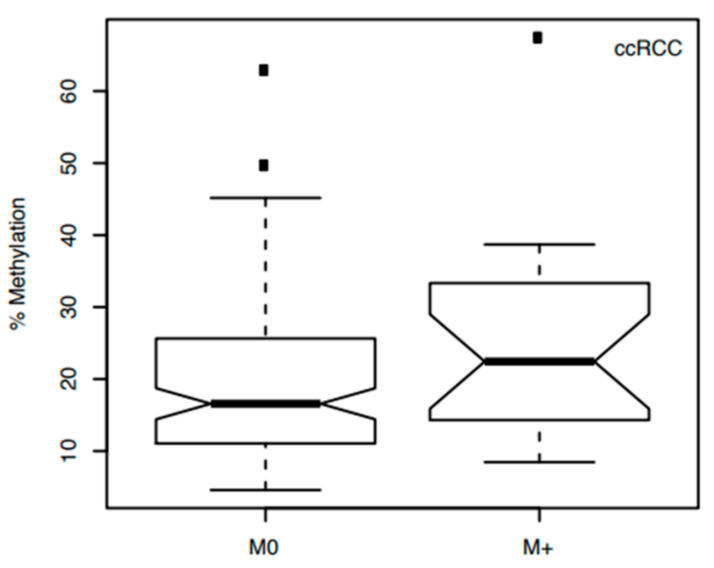

Figure 2. Box plot of INA (a), NHLH2 (b), and THBS4 (c) methylation in tumors without (M0) and with metastatic disease $(\mathrm{M}+)$ for the complete cohort (allRCC) and ccRCC subgroups. Medians are shown with the estimated confidence interval (notches), $25 \%$ and $75 \%$ quartiles. Whiskers indicate the $99.3 \%$ interval (two-sided 1.5-fold interquartile range) and black squares the outliers for the relative methylation distributions. Corresponding $p$-values and odds ratios are presented in Table 3. 
Table 3. Bivariate logistic regression analysis of association of INA, NHLH2, and THBS4 methylation and clinicopathological characteristics.

\begin{tabular}{|c|c|c|c|c|c|c|}
\hline \multirow{3}{*}{ Methylation } & \multicolumn{4}{|c|}{ (a) Complete Cohort (allRCC) } & \multirow{2}{*}{\multicolumn{2}{|c|}{ THBS4 }} \\
\hline & \multicolumn{2}{|c|}{ INA } & \multicolumn{2}{|c|}{ nhlh2 } & & \\
\hline & OR $(95 \% \mathrm{CI})$ & $p$-value & OR $(95 \% \mathrm{CI})$ & $p$-value & OR $(95 \% \mathrm{CI})$ & $p$-value \\
\hline Metastasis (M0 vs. M1) & $1.05(1.02-1.09)$ & 0.002 & $1.05(1.02-1.07)$ & $<0.001$ & $1,04(1.01-1.07)$ & 0.008 \\
\hline Lymph node status (N0 vs. N1) & $1.04(1.00-1.09)$ & $<0.001$ & $1.05(1.02-1.09)$ & $<0.001$ & $1.04(1.01-1.07)$ & 0.021 \\
\hline Tumor stage (low vs. high $\mathrm{T}^{*}$ ) & $1.07(1.04-1.10)$ & $<0.001$ & $1.06(1.04-1.09)$ & $<0.001$ & $1.05(1.03-1.08)$ & $<0.001$ \\
\hline Differentiation (low vs. high $G^{* *}$ ) & $1.08(1.04-1.12)$ & $<0.001$ & $1.06(1.03-1.09)$ & $<0.001$ & $1.05(1.02-1.08)$ & $<0.001$ \\
\hline
\end{tabular}

(b) ccRCC Subgroup

\begin{tabular}{|c|c|c|c|c|c|c|}
\hline \multirow{2}{*}{ Methylation } & \multicolumn{2}{|c|}{ INA } & \multicolumn{2}{|c|}{ NHLH2 } & \multicolumn{2}{|c|}{ THBS4 } \\
\hline & OR $(95 \% \mathrm{CI})$ & $p$-value & OR $(95 \% \mathrm{CI})$ & $p$-value & OR $(95 \% \mathrm{CI})$ & $p$-value \\
\hline Metastasis (M0 vs. M1) & $1.05(1.01-1.09)$ & 0.019 & $1.03(1.00-1.07)$ & 0.026 & $1.04(1.00-1.08)$ & 0.048 \\
\hline Lymph node status (N0 vs. N1) & na $* * *$ & na ${ }^{* * *}$ & na ${ }^{* * *}$ & na ${ }^{* * *}$ & na $* * *$ & na ${ }^{* * *}$ \\
\hline Tumor stage (low vs. high $\mathrm{T}^{*}$ ) & $1.07(1.03-1.10)$ & $<0.001$ & $1.05(1.02-1.08)$ & $<0.001$ & $1.05(1.02-1.09)$ & 0.001 \\
\hline Differentiation (low vs. high $G^{* *}$ ) & $1.07(1.03-1.12)$ & $<0.001$ & $1.05(1.02-1.08)$ & $<0.001$ & $1.04(1.01-1.08)$ & 0.021 \\
\hline
\end{tabular}

Note that statistical results of covariate age are not shown as statistical significance was either not reached (ccRCC) group or low ORs of $0.95-0.96$ with $p$-values from $p=0.02-0.05$ were obtained indicating weak model effects Abbreviations: vs. versus; na not available; OR odds ratio; $95 \%$ CI 95\% confidence interval ${ }^{*}$ Low defined as T1 and T2; high defined as T3 and T4; ** Low defined as G1, G2; high defined as $\geq \mathrm{G} 3$; *** Due to small group sizes no statistics available.
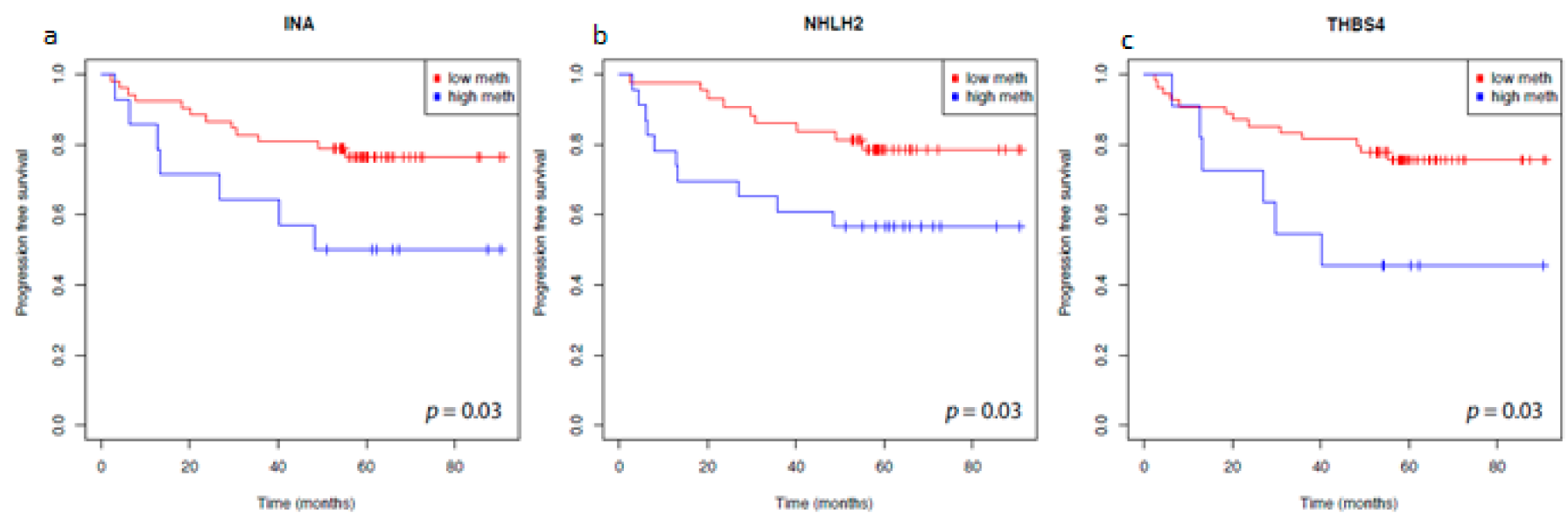

Figure 3. Kaplan-Meier survival analysis of INA (a), NHLH2 (b) and THBS4 (c) and progression free survival. Blue curve, patients with methylation levels above the gene-specific optimum cut-off. Red curve, patients with methylation levels below the gene-specific optimum cut-off. Optimized cut-off values applied for dichotomization were $24 \%$ (INA), $11 \%$ (NHLH2), and 25\% (THBS4).

\subsection{INA, NHLH2, and THBS4 Associated Candidate Loci Exhibit Tissue-Specific Hypermethylation in Tumor and Metastatic Tissues}

To analyze whether the candidate genes have tumor-specific hypermethylation, we measured 120, 141, and 132 corresponding pairs of adN and tumor tissue specimens for methylation of INA, NHLH2, and THBS4 (Figure 4a). Evaluation of INA was limited to the ccRCC tissue pairs due to a possible effect of histology on methylation. In contrast, NHLH2 and THBS4 could be analyzed independent from tumor histology. We found significant tumor-specific hypermethylation for all of the candidate genes in the paired tissue comparisons $\left(p=3.72 \times 10^{-24}, 3.17 \times 10^{-13}, 1.58 \times 10^{-19}\right)$.

Methylation of the INA, NHLH2, and THBS4 loci was also measured in a subset of 136-142 primary tumor tissues free of lymph node or distant metastasis and a total of 202 cancer metastatic tissues isolated from 100 renal cell cancer patients suffering from metachronous metastatic disease (Figure $4 \mathrm{~b}$, Table 4). Relative fold-changes in mean 
methylation of $1.44,1.91$, and 1.57 was detected for the metastatic tissue groups compared to localized primary tumor tissues, showing uniformly metastasis-specific hypermethylation for each of the candidate genes $\left(p=7.88 \times 10^{-8}, 5.57 \times 10^{-10}, 2.06 \times 10^{-7}\right)$. Interestingly, methylation as observed in some of the multiple metastases available for a subset of primary tumors was heterogeneous and reached high methylation values of more than $80 \%$ overall.

a)

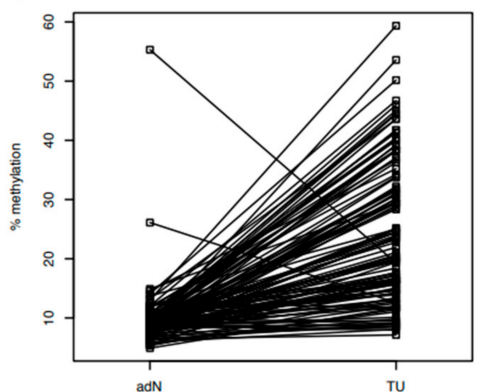

b)

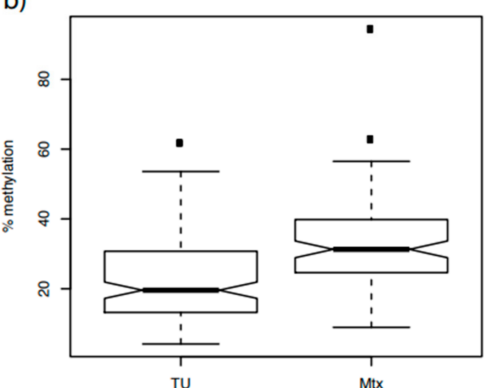

NHLH2
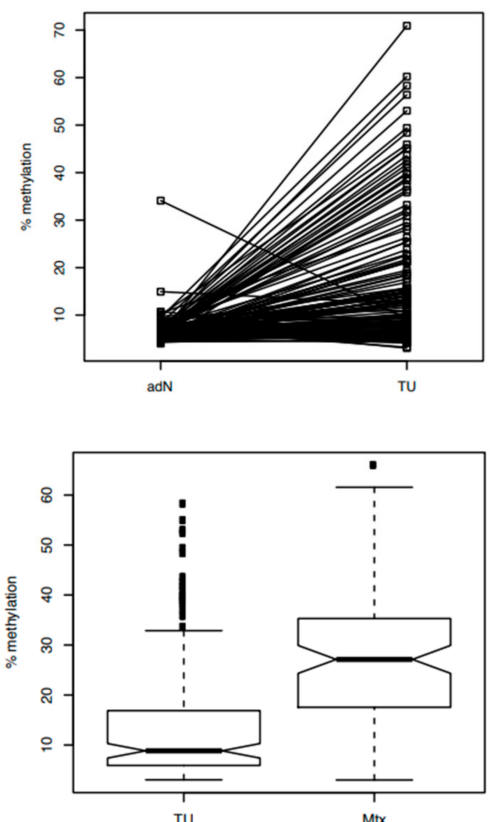

THBS4
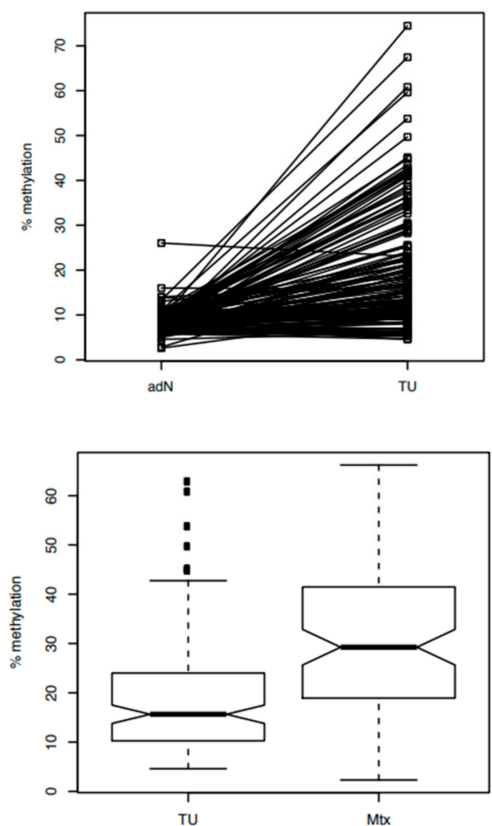

Figure 4. (a) Strip chart presentation of the hypermethylation analysis of INA, NHLH2, and THBS4 in paired adjacent normal tissue $(\mathrm{adN})$ and renal tumors (TU) samples. The corresponding statistical analysis revealed significant tumor-specific hypermethylation for all candidate genes $\left(p=3.72 \times 10^{-24}\right.$, $3.17 \times 10^{-13}, 1.58 \times 10^{-19}$ ). (b) Box plot of INA, NHLH2, and THBS4 methylation in independent tissue sample groups representing localized primary tumor and metastatic tissue samples. All of the candidate genes demonstrated metastatic tissue-specific hypermethylation $\left(p=7.88 \times 10^{-8}\right.$, $5.57 \times 10^{-10}, 2.06 \times 10^{-7}$ respectively).

Table 4. Statistical association of INA, NHLH2, and THBS4 methylation and metastatic tissue in logistic regression analyses.

\begin{tabular}{lcccccc}
\hline \multirow{2}{*}{ Methylation } & \multirow{2}{*}{ Gene } & \multicolumn{2}{c}{ Mean Methylation (\%) } & \multirow{2}{*}{ OR (95\% CI) } & adjOR & $p$-Value \\
\cline { 3 - 4 } & & Tu & Mtx & & & \\
\hline \multirow{3}{*}{ TUvs. Mtx } & INA & 22.8 & 32.8 & $1.07(1.05-1.1)$ & 1.98 & $7.88 \times 10^{-8}$ \\
& NHLH2 & 14.4 & 27.4 & $1.07(1.05-1.1)$ & 2.47 & $5.57 \times 10^{-10}$ \\
& THBS4 & 19.4 & 30.4 & $1.06(1.04-1.08)$ & 1.85 & $2.06 \times 10^{-7}$ \\
\hline
\end{tabular}

Abbreviations: adjOR adjusted odds ratio for difference of group means, OR odds ratio, 95\% CI 95\% Confidence interval, TU tumor, Mtx metastatic tissue.

3.4. Combined CpG Site-Specific DNA Methylation Is Informative of the Metastatic Disease State in Unsupervised and Supervised Statistical Analysis

To investigate whether methylation levels provide information supporting molecular identification of renal tumor tissues exhibiting metastatic disease (i.e., primary tumor tissue with proven $\mathrm{M}+$ state or $\mathrm{Mtx}$ ), a CpG loci-centric evaluation was carried out by performing both unsupervised and supervised classification of samples.

Unsupervised analysis was carried out following a comparison of various clustering and partition methods aiming to identify the most stable sample clusters, including bootstrapping and cross validation of samples. We found that k-means partitioning with 
three centers provided the most stable patient clusters, with Jaccard indices of $0.96,0.88$, and 0.81 , respectively. A heatmap of the corresponding k-means clustering (Figure 5) shows the three patient consensus clusters, approximately characterized by low (cluster 1), median (cluster 2), and high (cluster 3) average methylation levels. Statistical analysis of the corresponding matching table (Table 5) revealed that patient clusters were not independent from the metastatic disease state of tissues $\left(p=1.1 \times 10^{-10}\right.$, chi-squared test), and the corresponding mosaic plot demonstrated that clusters 2 and 3 included higher fractions of metastatic RCC tissues (Figure 6, blue groups in clusters 2 and 3 for metastatic disease column), whereas cluster 1 contained significantly more M0 tumors than expected by chance (Figure 6, blue group in cluster 1 for non-metastatic disease column). Interestingly, clustering of $\mathrm{CpG}$ sites in the heatmap (Figure 5) demonstrated that, in general, the smallest distances were observed for directly neighboring CpG loci and, thus, in large part matched the physical neighborhoods of $\mathrm{CpG}$ sites.

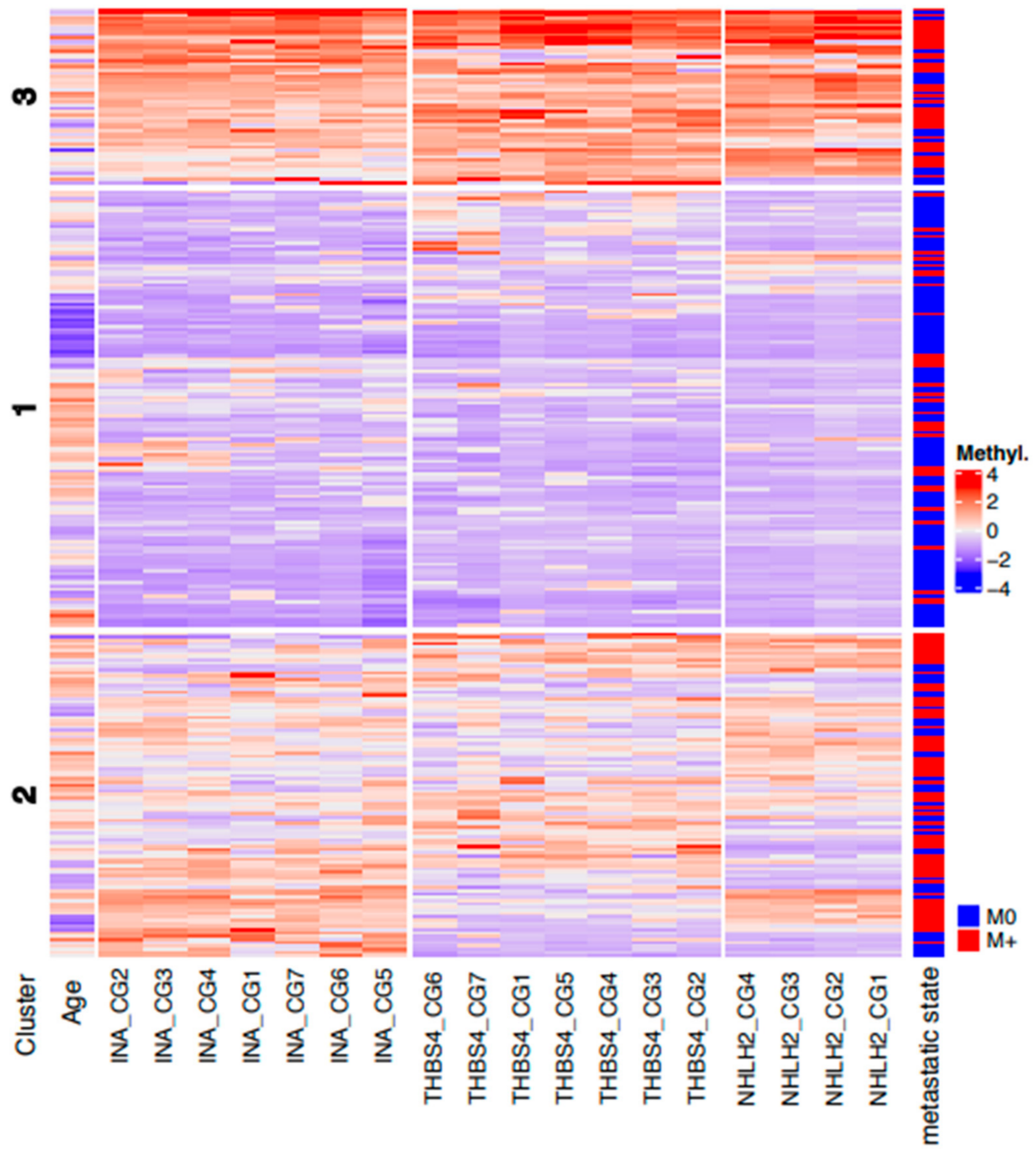

Figure 5. Heat map of unsupervised partitioning of the CpG site-specific methylation as observed in all tumor and metastatic tissue samples. Rows show patient- and sample-specific methylation data following normalization and color coding as indicated (from blue: minimum methylation to red: high methylation). The three patient clusters show most stable consensus clusters obtained by kmeans partitioning. Columns present the clustered normalized ages of patients and CpG site-specific methylation data. For comparison sample corresponding metastatic disease state (M0: localized primary tumors, $\mathrm{M}+$ : primary metastatic tumors or metastatic tissue samples) are presented. 
Table 5. Matching of unsupervised clustering and metastatic disease state.

\begin{tabular}{ccc}
\hline Cluster & $\begin{array}{c}\text { Patients Without Metastasis } \\
\text { (M0) }\end{array}$ & $\begin{array}{c}\text { Patients with Metastatic Disease State } \\
\text { (M+, Mtx) }\end{array}$ \\
\hline Cluster 1 & 103 & 33 \\
\hline Cluster 2 & 42 & 66 \\
\hline Cluster 3 & 15 & 33 \\
\hline
\end{tabular}

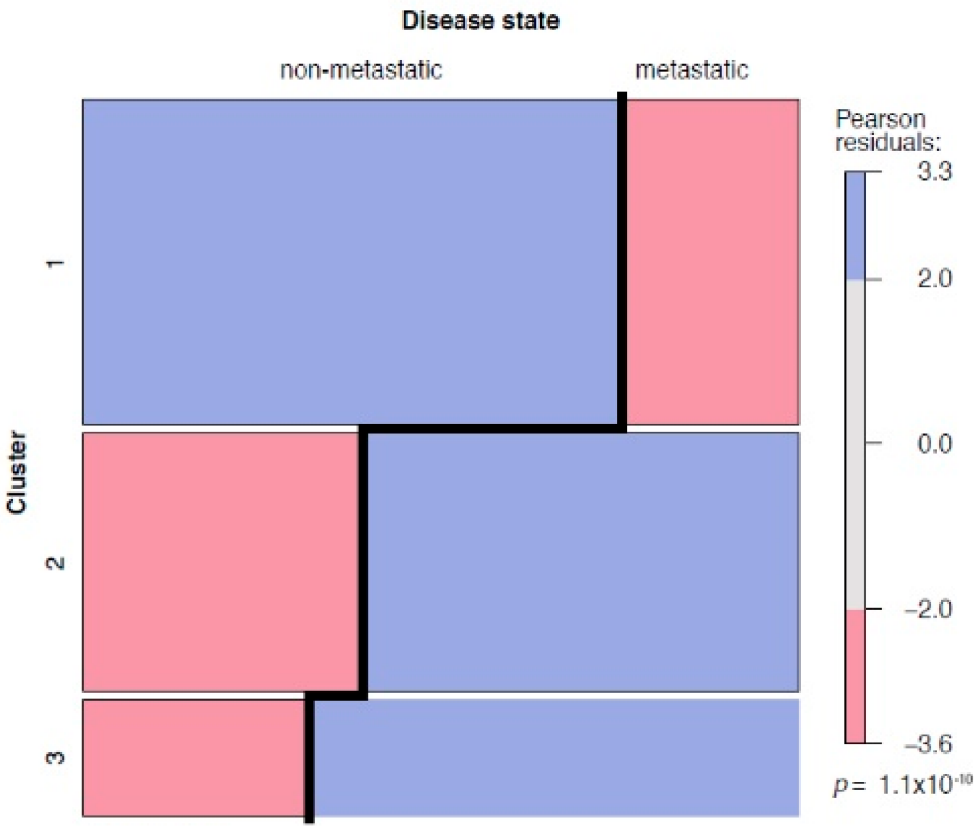

Figure 6. Left and right columns show the associations of clusters with either non-metastatic (left column, primary tumor M0 group) or metastatic disease state (right column, primary tumor M+ group and metastatic tissue Mtx group). Blue boxes indicate over-represented disease states in a cluster (Pearson residuals $>2$ ), whereas red boxes correspond to under-represented disease states (Pearson residuals $<-2$ ), providing statistical evidence that clustering is not independent from the metastatic disease state $\left(p=1.1 \times 10^{-10}\right)$.

Supervised statistical analysis required prior completion of data by imputing 29 of 2140 $(1.36 \%)$ and 35 of $2160(1.62 \%)$ missing values in the training and test cohorts, eventually providing 107 (58 tumors, 49 metastases) and 108 (61 tumors, 47 metastases) final cases for analysis. Applying the optimized random forest classification model obtained by resampling the training cohorts ( 25 bootstrapped repetitions, $\operatorname{mtry}=2$, splitrule $=$ gini) to the unknown test data, a comparison of the real and predicted status of the localized tumor or metastatic tissue in a confusion table revealed 35 true positive, 16 false positive, 45 true negative, and 12 false negative classifications. Therefore, prediction of the independent test cohort demonstrated an accuracy of 0.73 (95\% CI: $0.64-0.81, p=4.93 \times 10^{-6}$, one-sided binomial test in which accuracy is greater than the no information rate of 0.52$)$. Classifiers did not demonstrate different proportions of errors for the training and test data $(p=0.46$, McNemar's test). Sensitivity and specificity were 0.74 (95\% CI: $0.61-0.85)$ and 0.72 (95\% CI: 0.60-0.82), respectively. The positive likelihood ratio (PLR) and negative likelihood ratio (NLR) were 2.67 and 0.35 , respectively.

Importance analysis of the variables suggested that 6 of the $7(86 \%)$ INA, 2 of the 4 (50\%) NHLH2, and 2 of the 7 (29\%) THBS4 annotated CpG loci were the most important predictors in the random forest classification model when using the mean decrease in gini and times_a_root parameters as measures (Figure S1). 


\section{Discussion}

In the present study, we analyzed whether candidate markers, DNA methylated loci in the INA, NHLH2, and THBS4 genes, show an association with metastasis in RCC and could contribute to predicting the metastatic potential of renal cancer by providing new information on the biomarker signatures of aggressive disease.

In a gene-centric statistical evaluation of INA, NHLH2, and THBS4 methylation data, we found a uniform association of increased methylation with both the metastatic state of primary tumors and the metastatic tissue itself. Therefore, findings from in silico analyses of the TCGA KIRC data were confirmed for all of the candidate genes in independent tissue cohorts and by using a different method of methylation detection. Interestingly, this could also be achieved for the NHLH2 loci, despite some genomic distance between the pyrosequencing assay and candidate loci location. Neither the KIRC study nor the large part of molecular analysis of RCC include an analysis of metastatic tissue from primary RCC. Thus, to the best of our knowledge, only two studies have reported metastatic tissue-specific alterations in the DNA methylation of RUNX3 and TBR1 [21,62]. Although our findings of metastatic hypermethylation of INA, NHLH2, and THBS4 do not allow functional conclusions, it seems that cells carrying these epialterations are preserved, or even expanded, in RCC metastases. Therefore, the corresponding genes are natural candidates for further studies aiming to analyze epithelial-mesenchymal or mesenchymalepithelial transitions. In addition, the hypothetical functional relevance is supported by our finding of the tumor-specific hypermethylation of all three candidates considering that hypermethylation is frequently followed by epigenetic silencing of tumor suppressor genes and subsequent functional changes in RCC [15]. In line with this, gene silencing by hypermethylation and an association with more invasive tumors was recently reported for INA and THBS4 in other tumor entities [36,48]. Considering our finding of both tumor-specific hypermethylation and an additional increase in the methylation of genes in metastatic tissues, the hypothesis that these epialterations may indicate an increased metastatic potential of cells at an early state of tumor development is supported. Notably, all of our statistical analyses interrogating possible associations of candidate loci methylation with adverse clinicopathological parameters, as well as the survival of patients, point to candidate loci methylation as a characteristic of aggressive cancers.

Unsupervised statistical analyses using $\mathrm{CpG}$ site-specific methylation data for the INA, NHLH2, and THBS4 loci showed that tissue samples can be partitioned into three stable clusters that are not independent from the metastatic status of tissues. Nevertheless, detailed comparisons of the assigned clusters and metastatic disease state resulted in a number of tumor misclassifications. This had to be expected considering that a subset of tumors and derived metastases are not affected by INA, NHLH2, or THBS4 hypermethylation, automatically increasing the number of false negative classifications. Moreover, heterogeneous methylation patterns may not give rise to distinct and stable clustering, increasing the chance of misclassification within larger but more stable clusters. In an analogous but reversed manner, some false positive classifications may also be traced back to this effect. However, both phenomena could probably be minimized by expanding the sample cohorts. Interestingly, a considerable number of tumors within higher-methylated clusters 2 and 3 exhibit a homogenously high level of methylation but are classified as non-metastatic disease and appear as apparently false positives. Answering the highly relevant question of whether such tumors may be candidates for metachronous metastasis will, unfortunately, require the setup of a specific tissue cohort and, therefore, could not be addressed in the current study.

Methylation panels combining the $\mathrm{CpG}$ methylation of different candidate genes were previously reported to be associated with patient survival, with more robust statistical results and improved performance compared to clinical prognostic models [25,63-65]. Moreover, in view of the complex molecular architecture of alterations observed during tumorigenesis and metastasis and the individual variation of tumors, biomarker signatures that are subject to subsequent continuous extension, reevaluation, and reselection, rather 
than single markers, may be useful for a specific diagnostic task. Our supervised classification analysis of single CpG site methylation information using independent training and test data subsets and random forest analysis revealed that methylation information for a subset of 10 candidate loci from the total of 18 INA, NHLH2, and THBS4 annotated CpG sites already permits the identification of tissue samples with a metastatic disease state in an otherwise unknown tissue cohort with good accuracy. The diagnostic parameters obtained for supervised classification of the test samples are already roughly within the framework of parameters that are characteristic for medical tests [66]. Thus, the inclusion and selection of additional informative candidate loci seems to be a realistic means to achieve the level of accuracy required in order to translate the parameters into widely used diagnostics. The potential value of such measurements has decisively improved with recent findings showing that adjuvant treatment with pembrolizumab is beneficial for RCC patients with high-risk tumors [10]. Thus, future involvement of methylation-based signatures in prognostic models have the potential to improve risk stratification for adjuvant treatments $[10,65]$.

\section{Conclusions}

In conclusion, our analyses demonstrate the informativity of INA, NHLH2, and THBS4 CpG methylation for tissue-based prediction of the metastatic potency of RCC tissues. Thus, these epigenetic markers may be part of a potential tissue biomarker signature for the detection of aggressive disease development in localized RCC.

Supplementary Materials: The following are available online at https:/ /www.mdpi.com/article/10 .3390 / cancers14010039/s1: Table S1: Primer sequences, sequence to analyze and genomic position of the analyzed region for pyrosequencing, Figure S1: Variable of importance analysis of the random forest classification of tissue samples.

Author Contributions: Conceptualization: J.S., I.P., and M.A.K.; methodology: J.S. and I.P.; DNA extraction, bisulfite treatment of DNA and methylation analyses: N.D., C.R. and J.M.M.; writingoriginal draft preparation, review and editing: O.K., J.S., I.P. and J.H.; visualization: O.K., J.S. and I.P.; statistical analysis: J.S.; selection, sampling of tissue: M.L. and J.H.; scientific discussion: M.A.K., P.F.T. and H.T. All authors have read and agreed to the published version of the manuscript.

Funding: This research received no external funding.

Institutional Review Board Statement: The study was conducted according to the guidelines of the Declaration of Helsinki and approved by the ethical board of Eberhard Karls University Tuebingen (Head Prof. Jaschonek) and the ethical board of Hanover Medical School (Head Prof. Engeli) under vote no. 128/2003V (2003) and 1213-2011 (2011/10/14).

Informed Consent Statement: Informed consent was obtained from all subjects involved in the study.

Data Availability Statement: The anonymized datasets used and/or analyzed during the current study are available from the corresponding author upon reasonable request. Due to the General Data Protection Regulation (Art.5 DSGVO), we are not allowed to share sensitive data within an open data-sharing platform.

Conflicts of Interest: The authors declare no conflict of interest.

\section{References}

1. Capitanio, U.; Bensalah, K.; Bex, A.; Boorjian, S.A.; Bray, F.; Coleman, J.; Gore, J.L.; Sun, M.; Wood, C.; Russo, P. Epidemiology of renal cell carcinoma. Eur. Urol. 2019, 75, 74-84. [CrossRef] [PubMed]

2. Rossi, S.H.; Klatte, T.; Usher-Smith, J.; Stewart, G.D. Epidemiology and screening for renal cancer. World J. Urol. 2018, 36, 1341-1353. [CrossRef]

3. Graham, J.; Heng, D.Y.C.; Brugarolas, J.; Vaishampayan, U. Personalized management of advanced kidney cancer. Am. Soc. Clin. Oncol. Educ. Book 2018, 38, 330-341. [CrossRef] [PubMed]

4. Patel, H.D.; Gupta, M.; Joice, G.A.; Srivastava, A.; Alam, R.; Allaf, M.E.; Pierorazio, P.M. Clinical stage migration and survival for renal cell carcinoma in the United States. Eur. Urol. Oncol. 2019, 2, 343-348. [CrossRef] [PubMed] 
5. Kotecha, R.R.; Motzer, R.J.; Voss, M.H. Towards individualized therapy for metastatic renal cell carcinoma. Nat. Rev. Clin. Oncol. 2019, 16, 621-633. [CrossRef] [PubMed]

6. Klatte, T.; Rossi, S.H.; Stewart, G.D. Prognostic factors and prognostic models for renal cell carcinoma: A literature review. World J. Urol. 2018, 36, 1943-1952. [CrossRef] [PubMed]

7. Brunelli, M.; Eccher, A.; Gobbo, S.; Ficarra, V.; Novara, G.; Cossu-Rocca, P.; Bonetti, F.; Menestrina, F.; Cheng, L.; Eble, J.N.; et al. Loss of chromosome $9 \mathrm{p}$ is an independent prognostic factor in patients with clear cell renal cell carcinoma. Mod. Pathol. 2008, 21, 1-6. [CrossRef]

8. Di Nunno, V.; Mollica, V.; Brunelli, M.; Gatto, L.; Schiavina, R.; Fiorentino, M.; Santoni, M.; Montironi, R.; Caliò, A.; Eccher, A.; et al. A meta-analysis evaluating clinical outcomes of patients with renal cell carcinoma harboring chromosome $9 \mathrm{P}$ loss. Mol. Diagn. Ther. 2019, 23, 569-577. [CrossRef] [PubMed]

9. Morris, M.R.; Maher, E.R. Epigenetics of renal cell carcinoma: The path towards new diagnostics and therapeutics. Genome Med. 2010, 2, 59. [CrossRef]

10. Choueiri, T.K.; Tomczak, P.; Park, S.H.; Venugopal, B.; Ferguson, T.; Chang, Y.-H.; Hajek, J.; Symeonides, S.N.; Lee, J.L.; Sarwar, N.; et al. Adjuvant pembrolizumab after nephrectomy in renal-cell carcinoma. N. Engl. J. Med. 2021, 385, 683-694. [CrossRef] [PubMed]

11. Mancini, M.; Righetto, M.; Noessner, E. Checkpoint inhibition in bladder cancer: Clinical expectations, current evidence, and proposal of future strategies based on a tumor-specific immunobiological approach. Cancers 2021, 13, 6016. [CrossRef] [PubMed]

12. The Cancer Genome Atlas Research Network. Comprehensive molecular characterization of clear cell renal cell carcinoma. Nature 2013, 499, 43-49. [CrossRef] [PubMed]

13. The Cancer Genome Atlas Research Network. Comprehensive molecular characterization of papillary renal-cell carcinoma. $N$. Engl. J. Med. 2016, 374, 135-145. [CrossRef] [PubMed]

14. Ricketts, C.J.; De Cubas, A.A.; Fan, H.; Smith, C.C.; Lang, M.; Reznik, E.; Bowlby, R.; Gibb, E.A.; Akbani, R.; Beroukhim, R.; et al. The cancer genome atlas comprehensive molecular characterization of renal cell carcinoma. Cell Rep. 2018, 23, 313-326. [CrossRef] [PubMed]

15. Morris, M.R.; Ricketts, C.; Gentle, D.; Abdulrahman, M.; Clarke, N.; Brown, M.; Kishida, T.; Yao, M.; Latif, F.; Maher, E.R. Identification of candidate tumour suppressor genes frequently methylated in renal cell carcinoma. Oncogene 2010, 29, $2104-2117$. [CrossRef]

16. Peters, I.; Dubrowinskaja, N.; Hennenlotter, J.; Antonopoulos, W.; Von Klot, C.; Tezval, H.; Stenzl, A.; Kuczyk, M.; Serth, J. DNA methylation of neural EGFL like 1 (NELL1) is associated with advanced disease and the metastatic state of renal cell cancer patients. Oncol. Rep. 2018, 40, 3861-3868. [CrossRef]

17. Peters, I.; Gebauer, K.; Dubrowinskaja, N.; Atschekzei, F.; Kramer, M.W.; Hennenlotter, J.; Tezval, H.; Abbas, M.; Scherer, R.; Merseburger, A.S.; et al. GATA5 CpG island hypermethylation is an independent predictor for poor clinical outcome in renal cell carcinoma. Oncol. Rep. 2014, 31, 1523-1530. [CrossRef]

18. Tezval, H.; Dubrowinskaja, N.; Peters, I.; Reese, C.; Serth, K.; Atschekzei, F.; Hennenlotter, J.; Stenzl, A.; Kuczyk, M.A.; Serth, J. Tumor specific epigenetic silencing of corticotropin releasing hormone-binding protein in renal cell carcinoma: Association of hypermethylation and metastasis. PLoS ONE 2016, 11, e0163873. [CrossRef]

19. Katzendorn, O.; Peters, I.; Dubrowinskaja, N.; Tezval, H.; Tabrizi, P.F.; von Klot, C.A.; Hennenlotter, J.; Lafos, M.; Kuczyk, M.A.; Serth, J. DNA Methylation of tumor associated calcium signal transducer 2 (TACSTD2) loci shows association with clinically aggressive renal cell cancers. BMC Cancer 2021, 21, 444. [CrossRef]

20. Costa, V.L.; Henrique, R.; Ribeiro, F.R.; Pinto, M.; Oliveira, J.; Lobo, F.; Teixeira, M.R.; Jerónimo, C. Quantitative promoter methylation analysis of multiple cancer-related genes in renal cell tumors. BMC Cancer 2007, 7, 133. [CrossRef]

21. Serth, J.; Peters, I.; Dubrowinskaja, N.; Reese, C.; Albrecht, K.; Klintschar, M.; Lafos, M.; Grote, A.; Becker, A.; Hennenlotter, J.; et al. Age-, tumor-, and metastatic tissue-associated DNA hypermethylation of a T-box brain 1 locus in human kidney tissue. Clin. Epigenet. 2020, 12, 33. [CrossRef]

22. Atschekzei, F.; Hennenlotter, J.; Jänisch, S.; Großhennig, A.; Tränkenschuh, W.; Waalkes, S.; Peters, I.; Dörk, T.; Merseburger, A.S.; Stenzl, A.; et al. SFRP1 CpG island methylation locus is associated with renal cell cancer susceptibility and disease recurrence. Epigenetics 2012, 7, 447-457. [CrossRef]

23. Gebauer, K.; Peters, I.; Dubrowinskaja, N.; Hennenlotter, J.; Abbas, M.; Scherer, R.; Tezval, H.; Merseburger, A.S.; Stenzl, A.; Kuczyk, M.A.; et al. Hsa-Mir-124-3 CpG island methylation is associated with advanced tumours and disease recurrence of patients with clear cell renal cell carcinoma. Br. J. Cancer 2013, 108, 131-138. [CrossRef] [PubMed]

24. Deckers, I.A.G.; Schouten, L.J.; Van Neste, L.; van Vlodrop, I.J.H.; Soetekouw, P.M.M.B.; Baldewijns, M.M.L.L.; Jeschke, J.; Ahuja, N.; Herman, J.G.; van den Brandt, P.A.; et al. Promoter methylation of CDO1 identifies clear-cell renal cell cancer patients with poor survival outcome. Clin. Cancer Res. 2015, 21, 3492-3500. [CrossRef]

25. Van Vlodrop, I.J.H.; Joosten, S.C.; Meyer, T.D.; Smits, K.M.; Neste, L.V.; Melotte, V.; Baldewijns, M.M.L.L.; Schouten, L.J.; van den Brandt, P.A.; Jeschke, J.; et al. A four-gene promoter methylation marker panel consisting of GREM1, NEURL, LAD1, and NEFH predicts survival of clear cell renal cell cancer patients. Clin. Cancer Res. 2017, 23, 2006-2018. [CrossRef] [PubMed]

26. Peters, I.; Dubrowinskaja, N.; Abbas, M.; Seidel, C.; Kogosov, M.; Scherer, R.; Gebauer, K.; Merseburger, A.S.; Kuczyk, M.A.; Grünwald, V.; et al. DNA methylation biomarkers predict progression-free and overall survival of metastatic renal cell cancer (MRCC) treated with antiangiogenic therapies. PLoS ONE 2014, 9, e91440. [CrossRef] 
27. Dubrowinskaja, N.; Gebauer, K.; Peters, I.; Hennenlotter, J.; Abbas, M.; Scherer, R.; Tezval, H.; Merseburger, A.S.; Stenzl, A.; Grünwald, V.; et al. Neurofilament heavy polypeptide CpG island methylation associates with prognosis of renal cell carcinoma and prediction of antivascular endothelial growth factor therapy response. Cancer Med. 2014, 3, 300-309. [CrossRef] [PubMed]

28. Joosten, S.C.; Deckers, I.A.; Aarts, M.J.; Hoeben, A.; van Roermund, J.G.; Smits, K.M.; Melotte, V.; van Engeland, M.; Tjan-Heijnen, V.C. Prognostic DNA methylation markers for renal cell carcinoma: A systematic REVIEW. Epigenomics 2017, 9, $1243-1257$. [CrossRef] [PubMed]

29. Peters, I.; Merseburger, A.S.; Tezval, H.; Lafos, M.; Tabrizi, P.F.; Mazdak, M.; Wolters, M.; Kuczyk, M.A.; Serth, J.; von Klot, C.-A.J. The prognostic value of DNA methylation markers in renal cell cancer: A systematic review. KCA 2020, 4, 3-13. [CrossRef]

30. Yuan, A.; Rao, M.V.; Sasaki, T.; Chen, Y.; Kumar, A.; Veeranna, N.; Liem, R.K.H.; Eyer, J.; Peterson, A.C.; Julien, J.-P.; et al. Alpha-internexin is structurally and functionally associated with the neurofilament triplet proteins in the mature CNS. J. Neurosci. 2006, 26, 10006-10019. [CrossRef]

31. Yuan, A.; Rao, M.V.; Veeranna, N.; Nixon, R.A. Neurofilaments and neurofilament proteins in health and disease. Cold Spring Harb. Perspect. Biol. 2017, 9, a018309. [CrossRef]

32. Ducray, F.; Mokhtari, K.; Crinière, E.; Idbaih, A.; Marie, Y.; Dehais, C.; Paris, S.; Carpentier, C.; Dieme, M.-J.; Adam, C.; et al. Diagnostic and prognostic value of alpha internexin expression in a series of 409 gliomas. Eur. J. Cancer 2011, 47, 802-808. [CrossRef] [PubMed]

33. Suh, J.H.; Park, C.-K.; Park, S.-H. Alpha internexin expression related with molecular characteristics in adult glioblastoma and oligodendroglioma. J. Korean Med. Sci. 2013, 28, 593-601. [CrossRef] [PubMed]

34. Wang, Y.; Chen, Y.; Li, X.; Hu, W.; Zhang, Y.; Chen, L.; Chen, M.; Chen, J. Loss of expression and prognosis value of alphainternexin in gastroenteropancreatic neuroendocrine neoplasm. BMC Cancer 2018, 18, 691. [CrossRef]

35. Song, Y.-L.; Yu, R.; Qiao, X.-W.; Bai, C.-M.; Lu, C.-M.; Xiao, Y.; Zhong, D.-R.; Chen, J.; Zhao, Y.-P.; Zhang, T.-P.; et al. Prognostic relevance of UCH-L1 and $\alpha$-internexin in pancreatic neuroendocrine tumors. Sci. Rep. 2017, 7, 2205. [CrossRef]

36. Li, Y.; Bai, L.; Yu, H.; Cai, D.; Wang, X.; Huang, B.; Peng, S.; Huang, M.; Cao, G.; Kaz, A.M.; et al. Epigenetic inactivation of $\alpha$-internexin accelerates microtubule polymerization in colorectal cancer. Cancer Res. 2020, 80, 5203-5215. [CrossRef] [PubMed]

37. Murre, C.; Bain, G.; van Dijk, M.A.; Engel, I.; Furnari, B.A.; Massari, M.E.; Matthews, J.R.; Quong, M.W.; Rivera, R.R.; Stuiver, M.H. Structure and function of helix-loop-helix proteins. Biochim. Biophys. Acta (BBA)—Gene Struct. Express. 1994, 1218, 129-135. [CrossRef]

38. Atchley, W.R.; Fitch, W.M. A natural classification of the basic helix-loop-helix class of transcription factors. Proc. Natl. Acad. Sci. USA 1997, 94, 5172-5176. [CrossRef]

39. Leon, S.; Talbi, R.; McCarthy, E.A.; Ferrari, K.; Fergani, C.; Naule, L.; Choi, J.H.; Carroll, R.S.; Kaiser, U.B.; Aylwin, C.F.; et al. Sex-specific pubertal and metabolic regulation of kiss1 neurons via Nhlh2. eLife 2021, 10, e69765. [CrossRef]

40. AL Rayyan, N.; Zhang, J.; Burnside, A.S.; Good, D.J. Leptin signaling regulates hypothalamic expression of nescient helix-loophelix 2 (Nhlh2) through signal transducer and activator 3 (Stat3). Mol. Cell. Endocrinol. 2014, 384, 134-142. [CrossRef]

41. Aoyama, M.; Ozaki, T.; Inuzuka, H.; Tomotsune, D.; Hirato, J.; Okamoto, Y.; Tokita, H.; Ohira, M.; Nakagawara, A. LMO3 interacts with neuronal transcription factor, HEN2, and acts as an oncogene in neuroblastoma. Cancer Res. 2005, 65, 4587-4597. [CrossRef]

42. Adams, J.C.; Lawler, J. The Thrombospondins. Cold Spring Harb. Perspect. Biol. 2011, 3, a009712. [CrossRef] [PubMed]

43. Muppala, S.; Xiao, R.; Krukovets, I.; Verbovetsky, D.; Yendamuri, R.; Habib, N.; Raman, P.; Plow, E.; Stenina-Adognravi, O. Thrombospondin-4 mediates TGF- $\beta$-induced angiogenesis. Oncogene 2017, 36, 5189-5198. [CrossRef] [PubMed]

44. Liu, J.; Cheng, G.; Yang, H.; Deng, X.; Qin, C.; Hua, L.; Yin, C. Reciprocal regulation of long noncoding RNAs THBS4-003 and THBS4 control migration and invasion in prostate cancer cell lines. Mol. Med. Rep. 2016, 14, 1451-1458. [CrossRef] [PubMed]

45. Su, F.; Zhao, J.; Qin, S.; Wang, R.; Li, Y.; Wang, Q.; Tan, Y.; Jin, H.; Zhu, F.; Ou, Y.; et al. Over-expression of thrombospondin 4 correlates with loss of MiR-142 and contributes to migration and vascular invasion of advanced hepatocellular carcinoma. Oncotarget 2017, 8, 23277-23288. [CrossRef]

46. Kim, M.S.; Choi, H.S.; Wu, M.; Myung, J.; Kim, E.J.; Kim, Y.S.; Ro, S.; Ha, S.E.; Bartlett, A.; Wei, L.; et al. Potential role of PDGFR $\beta$-associated THBS4 in colorectal cancer development. Cancers 2020, 12, 2533. [CrossRef]

47. Kuroda, K.; Horiguchi, A.; Asano, T.; Ito, K.; Asakuma, J.; Sato, A.; Yoshii, H.; Hayakawa, M.; Sumitomo, M.; Asano, T. Glucoseregulated protein 78 positivity as a predictor of poor survival in patients with renal cell carcinoma. Urol. Int. 2011, 87, 450-456. [CrossRef]

48. Greco, S.A.; Chia, J.; Inglis, K.J.; Cozzi, S.-J.; Ramsnes, I.; Buttenshaw, R.L.; Spring, K.J.; Boyle, G.M.; Worthley, D.L.; Leggett, B.A.; et al. Thrombospondin-4 is a putative tumour-suppressor gene in colorectal cancer that exhibits age-related methylation. $B M C$ Cancer 2010, 10, 494. [CrossRef]

49. Van Doorn, R.; Zoutman, W.H.; Dijkman, R.; de Menezes, R.X.; Commandeur, S.; Mulder, A.A.; van der Velden, P.A.; Vermeer, M.H.; Willemze, R.; Yan, P.S.; et al. Epigenetic profiling of cutaneous T-cell lymphoma: Promoter hypermethylation of multiple tumor suppressor genes including BCL7a, PTPRG, and P73. J. Clin. Oncol. 2005, 23, 3886-3896. [CrossRef]

50. Zhang, Y.; Fang, L.; Zang, Y.; Xu, Z. Identification of core genes and key pathways via integrated analysis of gene expression and DNA methylation profiles in bladder cancer. Med. Sci. Monit. 2018, 24, 3024-3033. [CrossRef]

51. R Core Team. R: A Language and Environment for Statistical Computing; R Foundation for Statistical Computing: Vienna, Austria, 2021. Available online: https: / /www.r-project.org (accessed on 20 July 2021). 
52. Waalkes, S.; Atschekzei, F.; Kramer, M.W.; Hennenlotter, J.; Vetter, G.; Becker, J.U.; Stenzl, A.; Merseburger, A.S.; Schrader, A.J.; Kuczyk, M.A.; et al. Fibronectin 1 MRNA expression correlates with advanced disease in renal cancer. BMC Cancer 2010, 10, 503. [CrossRef] [PubMed]

53. Lausen, B.; Schumacher, M. Maximally selected rank statistics. Biometrics 1992, 48, 73-85. [CrossRef]

54. van Buuren, S.; Groothuis-Oudshoorn, K. MICE: Multivariate imputation by chained equations in R. J. Stat. Softw. 2011, 45, 1-67. [CrossRef]

55. R ClusterTools Package. Available online: https://github.com/vzoche-golob/clustertools/blob/master/description (accessed on 1 November 2021).

56. Gu, Z.; Eils, R.; Schlesner, M. Complex heatmaps reveal patterns and correlations in multidimensional genomic data. Bioinformatics 2016, 32, 2847-2849. [CrossRef]

57. Meyer, D.; Zeileis, A.; Hornik, K. Vcd: Visualizing Categorical Data; R Package Version 1.4-9. 2021; R Foundation for Statistical Computing: Vienna, Austria, 2021.

58. Kuhn, M. Building predictive models in R using the caret package. J. Stat. Soft. 2008, 28, 1-35. [CrossRef]

59. Wright, M.N.; Ziegler, A. Ranger: A fast implementation of random forests for high dimensional data in C++ and R. J. Stat. Soft. 2017, 77, 1-17. [CrossRef]

60. Breiman, L. Random forests. Mach. Learn. 2001, 45, 5-32. [CrossRef]

61. Paluszynska, A.; Biecek, P.; Jiang, Y. RandomForestExplainer: Explaining and Visualizing Random Forests in Terms of Variable Importance. 2020. Available online: https: / / cran.r-project.org/package=randomforestexplainer (accessed on 1 August 2021).

62. Zheng, J.; Mei, Y.; Xiang, P.; Zhai, G.; Zhao, N.; Xu, C.; Liu, M.; Pan, Z.; Tang, K.; Jia, D. DNA methylation affects metastasis of renal cancer and is associated with TGF- $\beta$ /RUNX3 inhibition. Cancer Cell Int. 2018, 18, 56. [CrossRef] [PubMed]

63. Wei, J.-H.; Haddad, A.; Wu, K.-J.; Zhao, H.-W.; Kapur, P.; Zhang, Z.-L.; Zhao, L.-Y.; Chen, Z.-H.; Zhou, Y.-Y.; Zhou, J.-C.; et al. A CpG-methylation-based assay to predict survival in clear cell renal cell carcinoma. Nat. Commun. 2015, 6, 8699. [CrossRef]

64. Kang, H.W.; Park, H.; Seo, S.P.; Byun, Y.J.; Piao, X.-M.; Kim, S.M.; Kim, W.T.; Yun, S.-J.; Jang, W.; Shon, H.S.; et al. Methylation signature for prediction of progression free survival in surgically treated clear cell renal cell carcinoma. J. Korean Med. Sci. 2019, 34, e144. [CrossRef]

65. Joosten, S.C.; Odeh, S.N.O.; Koch, A.; Buekers, N.; Aarts, M.J.B.; Baldewijns, M.M.L.L.; Van Neste, L.; van Kuijk, S.; Schouten, L.J.; van den Brandt, P.A.; et al. Development of a prognostic risk model for clear cell renal cell carcinoma by systematic evaluation of DNA methylation markers. Clin. Epigenet. 2021, 13, 103. [CrossRef] [PubMed]

66. Power, M.; Fell, G.; Wright, M. Principles for high-quality, high-value testing. Evid. Based Med. 2013, 18, 5-10. [CrossRef] [PubMed] 